\title{
Relationship between peripheral airway function and patient-reported outcomes in COPD: a cross-sectional study
}

Akane Haruna ${ }^{1}$, Toru Oga ${ }^{2 * \dagger}$, Shigeo Muro ${ }^{1 \dagger}$, Tadashi Ohara ${ }^{1}$, Susumu Sato ${ }^{1}$, Satoshi Marumo ${ }^{1}$, Daisuke Kinose ${ }^{1}$ Kunihiko Terada', Michiyoshi Nishioka', Emiko Ogawa', Yuma Hoshino', Toyohiro Hirai', Kazuo Chin², Michiaki Mishima'

\begin{abstract}
Background: Health status, dyspnea and psychological status are important clinical outcomes in chronic obstructive pulmonary disease (COPD). However, forced expiratory volume in one second (FEV F $_{1}$ measured by spirometry, the standard measurement of airflow limitation, has only a weak relationship with these outcomes in COPD. Recently, in addition to spirometry, impulse oscillometry (IOS) measuring lung resistance (R) and reactance $(X)$ is increasingly being used to assess pulmonary functional impairment.

Methods: We aimed to identify relationships between IOS measurements and patient-reported outcomes in 65 outpatients with stable COPD. We performed pulmonary function testing, IOS, high-resolution computed tomography (CT), and assessment of health status using the St. George's Respiratory Questionnaire (SGRQ), dyspnea using the Medical Research Council (MRC) scale and psychological status using the Hospital Anxiety and Depression Scale (HADS). We then investigated the relationships between these parameters. For the IOS measurements, we used lung resistance at 5 and $20 \mathrm{~Hz}$ (R5 and R20, respectively) and reactance at $5 \mathrm{~Hz}$ (X5). Because R5 and R20 are regarded as reflecting total and proximal airway resistance, respectively, the fall in resistance from R5 to R20 (R5-R20) was used as a surrogate for the resistance of peripheral airways. X5 was also considered to represent peripheral airway abnormalities.
\end{abstract}

Results: R5-R20 and X5 were significantly correlated with the SGRQ and the MRC. These correlation coefficients were greater than when using other objective measurements of pulmonary function, R2O on the IOS and CT instead of R5-R20 and X5. Multiple regression analyses showed that R5-R20 or X5 most significantly accounted for the SGRQ and MRC scores.

Conclusions: IOS measurements, especially indices of peripheral airway function, are significantly correlated with health status and dyspnea in patients with COPD. Therefore, in addition to its simplicity and non-invasiveness, IOS may be a useful clinical tool not only for detecting pulmonary functional impairment, but also to some extent at least estimating the patient's quality of daily life and well-being.

\footnotetext{
* Correspondence: ogat@df7.so-net.ne.jp

† Contributed equally

²Department of Respiratory Care and Sleep Control Medicine, Graduate

School of Medicine, Kyoto University, Kyoto, Japan
} 


\section{Background}

Health status, dyspnea and psychological status of anxiety and depression are important outcomes in chronic obstructive pulmonary disease (COPD). Improved health status and relief of symptoms are listed as the goals of effective management in the Global Initiative for Chronic Obstructive Lung Disease (GOLD) [1].

Mortality is also an important outcome in COPD as it is ranked as high as a cause of death in the world [1]. The above-mentioned patient-reported outcomes can significantly predict mortality independently of airflow limitation evaluated by forced expiratory volume in one second $\left(\mathrm{FEV}_{1}\right)$ [2-4]. In fact, previous reports indicate that there are only weak correlations between these outcomes and $\mathrm{FEV}_{1}[5-8]$.

Recent studies suggest that impulse oscillometry (IOS) can detect airway abnormalities better than spirometry for assessing pulmonary function in COPD $[9,10]$, adult asthma [11-13], and dust exposure [14,15]. IOS measures lung resistance and reactance, and is a clinically promising method which is simple and non-invasive and does not require forced maneuvers [16,17].

Comparing $\mathrm{FEV}_{1}$ by spirometry and IOS, while $\mathrm{FEV}_{1}$ mainly measures expiratory flow at high and mid lung volumes [18], IOS can usefully measure both large and small airway resistance separately [14-17]. This feature of IOS may be important because the involvement of small airways in COPD is indicated [19-21].

In assessing COPD, high-resolution computed tomography (CT) also provides valuable information concerning parenchymal destruction and airway lesions. We have assessed the severity of emphysema by measuring the low attenuation area (LAA), and airway dimensions including evaluation of the luminal area and airway wall thickness of the right upper apical bronchus [22].

We hypothesized that there would be significant associations between patient- reported outcomes and pulmonary impairments evaluated with IOS in patients with COPD. Here, we performed a cross-sectional study evaluating three different objective assessments consisting of conventional pulmonary function tests, IOS and $\mathrm{CT}$, and compared them with subjective measurements of health status, dyspnea and psychological status in patients with COPD.

\section{Methods}

\section{Subjects}

We recruited 65 male outpatients with stable COPD, defined by the GOLD [1], at Kyoto University Hospital. The eligibility criteria included: 1 ) smoking history of more than 20 pack-years; 2) maximal $\mathrm{FEV}_{1}$ /forced vital capacity (FVC) ratio of less than $0.7 ; 3$ ) regular management and treatment at our outpatient clinic over 6 months; 4) no exacerbations in the previous 6 weeks; 5) no other lung diseases; 6) no uncontrolled comorbidities such as severe cardiovascular diseases and malignant disorders; and 7) having sufficient cognitive function to complete the questionnaire. Pulmonary function, IOS, $\mathrm{CT}$, health status, dyspnea, and psychological status were assessed on the same day. The research protocol was approved by the Ethics Committee of Kyoto University and the subjects gave written informed consent.

\section{Outcome measures \\ Pulmonary function}

Spirometry was performed according to the recommended method, as reported previously $[2,6,7]$. Residual volume (RV) and total lung capacity (TLC) were measured by the closed-circuit helium method, and carbon monoxide diffusing capacity $\left(\mathrm{DL}_{\mathrm{CO}}\right)$ was measured using a single-breath technique.

IOS

The impedance of the total respiratory system was measured using IOS (Erich Jaeger, Germany). Subjects underwent IOS and then spirometry 15 minutes after inhaling the bronchodilators salbutamol $(400 \mu \mathrm{g})$ and ipratropium bromide $(80 \mu \mathrm{g})[2,6,7]$. The superimposed pressure oscillations during normal-volume spontaneous breathing are composed of several frequencies, allowing the assessment of resistance $(\mathrm{R})$ and reactance $(\mathrm{X})$ at several frequencies simultaneously. The frequency range of the signal was from 5 to $35 \mathrm{~Hz}$. Subjects supported their cheeks to reduce upper airway shunting while impulses were applied during tidal breathing for $30 \mathrm{sec}-$ onds. In the present study, we used respiratory resistance at 5 and $20 \mathrm{~Hz}$ (R5 and R20, respectively) and reactance at $5 \mathrm{~Hz}$ (X5) for the analyses. R5 and R20 are regarded as reflecting total and proximal airway resistance, respectively, and the fall in resistance from R5 to R20 (R5-R20) was used as a surrogate for the resistance of peripheral airways, as reported previously [14-17,23-27]. Furthermore, X5, which may be determined by homogeneous distribution of ventilation, effective ventilation capacity, and compliance of the lung and chest wall, was also considered to represent peripheral airway abnormalities such as those caused by inflammation [15-17,23-25]. X5 was recently reported to be a useful and informative measurement due to its close relationship with conventional pulmonary function assessments in COPD [28].

\section{CT}

CT images were obtained using a multi-detector row scanner (Aquilion 64; Toshiba, Tokyo, Japan) with simultaneous acquisition of sixty-four $0.5 \mathrm{~mm}$ sections. Technical parameters were as follows: voltage $120 \mathrm{kVp}$, automatic electric current control, field of view 
$350 \mathrm{~mm}$, reconstruction algorithm, lung algorithm with automatic correction of beam hardening effect. Percentages of LAA (LAA\%) were analyzed according to a modified method that was previously reported from our department [29]. Unlike the original method, in the current study, we used multi-detector computed tomography (MDCT) that provided us with many slices, but without additional radiation exposure. Therefore, we used the slices from the upper margin of the aortic arch to the diaphragm to analyze LAA\%. Areas where CT numbers were less than $-200 \mathrm{HU}$ were defined as lung fields, and the cut-off level between LAA and normal lung density was defined as $-960 \mathrm{HU}[22,30]$.

For the analysis of airway dimensions, the right upper apical bronchus was measured in each subject using the method we had previously reported [22,30,31]. The area of the inner lumen and thickness of the airway wall was measured automatically from CT images. The diameter of the airway, the outer area of the airway, airway wall area (WA), and percentage wall area (WA\%) were calculated from the area of the inner lumen and thickness of the airway wall.

\section{Health status}

Health status was evaluated by the Japanese version of the St. George's Respiratory Questionnaire (SGRQ) $[2,6,7,32]$. It contains 50 items divided into 3 components of symptoms, activity and impacts, and a total score was also calculated, with scores ranging from 0 to 100. Lower scores indicate less impairment on the SGRQ.

\section{Dyspnea}

Severity of dyspnea was evaluated by the Japanese version of the modified Medical Research Council (MRC) scale $[6,7,33]$, which consists of a 5-point scale based on degrees of various physical activities that precipitate dyspnea. Lower scores indicate less impairment on the MRC scale.

\section{Psychological status}

Psychological status was evaluated by the Japanese version of the Hospital Anxiety and Depression Scale (HADS) $[6,7,34]$ which contains 14 items and consists of two subscales: anxiety and depression. Each item is rated on a four-point scale (0-3) where a score of 3 represents the worst state of anxiety or depression.

\section{Statistical analysis}

Results are expressed as mean \pm SD. Relationships between different objective measurements (pulmonary function testing, IOS and CT) and patient-reported outcomes were evaluated using Pearson's correlation coefficient tests. We have chosen to present all results as Pearson's correlation coefficients for ease of comprehension and comparison across relationships [35]. We also tested for significant differences between two correlation coefficients obtained from two different relationships in the same samples [36]. Next, we performed forward and backward stepwise multiple regression analyses to identify the variables that could best predict the health status and dyspnea scores, using the measurements of pulmonary function, IOS and CT as independent variables [6]. P values of less than 0.05 were considered to be statistically significant. All analyses were performed using the JMP (SAS Institute).

\section{Results}

\section{Baseline characteristics}

Baseline characteristics of the 65 male patients with COPD are presented in Table 1. Of these, 11 (17.0\%) were current smokers. COPD severity based on the GOLD [1] was mild in 12 patients (18.4\%), moderate in $30(46.2 \%)$, severe in $20(30.8 \%)$, and very severe in the remaining 3 patients (4.6\%).

\section{Relationships between IOS measurements, pulmonary function and $\mathbf{C T}$}

We examined the relationships between IOS measurements and other objective parameters of pulmonary function and CT. R20 showed a weak or non-significant correlation with R5-R20 and X5 ( $r$ (correlation coefficient $)=0.29, p=0.020$, and $r=-0.19, p=0.13$,

Table 1 Baseline characteristics $(n=65)$

\begin{tabular}{|c|c|c|}
\hline Characteristics & Mean \pm SD & Range \\
\hline Age (years) & $71 \pm 9$ & $46-87$ \\
\hline Height $(\mathrm{m})$ & $1.65 \pm 0.06$ & $1.50-1.80$ \\
\hline Body mass index $\left(\mathrm{kg} / \mathrm{m}^{2}\right)$ & $21.3 \pm 2.7$ & $15.42-29.0$ \\
\hline $\mathrm{FEV}_{1}(\mathrm{~L})$ & $1.64 \pm 0.64$ & $0.58-3.42$ \\
\hline $\mathrm{FEV}_{1}$ (\%predicted) & $58.8 \pm 19.7$ & $18.7-100.8$ \\
\hline $\mathrm{RV} / \mathrm{TLC}(\%)$ & $42.9 \pm 7.5$ & $27.7-59.4$ \\
\hline $\mathrm{DL}_{\mathrm{CO}} \mathrm{N}_{\mathrm{A}}(\mathrm{ml} / \mathrm{min} / \mathrm{mmHg} / \mathrm{L})$ & $2.76 \pm 1.06$ & $0.69-5.35$ \\
\hline $\mathrm{R} 20(\mathrm{kPa} / \mathrm{L} / \mathrm{s})$ & $0.24 \pm 0.07$ & $0.13-0.41$ \\
\hline R5-R20 (kPa/L/s) & $0.09 \pm 0.06$ & $-0.02-0.27$ \\
\hline X5 (kPa/L/s) & $-0.15 \pm 0.08$ & $-0.48--0.05$ \\
\hline LAA (\%) & $20.4 \pm 10.2$ & $2.5-44.5$ \\
\hline WA (\%) & $57.1 \pm 5.7$ & $44.9-71.6$ \\
\hline SGRQ symptoms (0-100) & $35.0 \pm 20.5$ & $0-90.6$ \\
\hline SGRQ activity (0-100) & $41.2 \pm 21.9$ & $0-92.5$ \\
\hline SGRQ impact (0-100) & $20.1 \pm 15.9$ & $0-63.2$ \\
\hline SGRQ total $(0-100)$ & $29.0 \pm 16.4$ & $1.6-62.3$ \\
\hline MRC (0-4) & $1.1 \pm 0.8$ & $0-4$ \\
\hline HADS anxiety (0-21) & $3.3 \pm 3.0$ & $0-12$ \\
\hline HADS depression (0-21) & $3.6 \pm 2.9$ & $0-12$ \\
\hline
\end{tabular}

Numbers in parentheses indicate theoretical score ranges.

$\mathrm{FEV}_{1}=$ forced expiratory volume in one second; $\mathrm{RV}=$ residual volume; $\mathrm{TLC}=$ total lung capacity; $\mathrm{DL}_{\mathrm{CO}}=$ carbon monoxide diffusing capacity; $\mathrm{V}_{\mathrm{A}}=$ alveolar volume $\mathrm{R}=$ resistance; $\mathrm{X}=$ reactance; $\mathrm{LAA}=$ low attenuation area; $\mathrm{WA}=$ wall area; SGRQ = St. George's Respiratory Questionnaire; MRC = Medical Research Council; HADS = Hospital Anxiety and Depression Scale 
respectively), indicating $\mathrm{R} 20$ reflects different physiological parameters from R5-R20 and X5. In contrast, there was a strong association between R5-R20 and X5 $(r=-0.87, p<0.001)$, indicating that these two peripheral airway functional indices could reflect similar events. R20 was significantly but weakly correlated with $\mathrm{FEV}_{1}(r=-0.29, p=0.018)$. R5-R20 and X5 were moderately significantly correlated with $\mathrm{FEV}_{1}(r=-0.69$, $p<0.001$ and $r=0.61, p<0.001$, respectively) and RV/ TLC $(r=0.49, p<0.001$ and $r=-0.54, p<0.001$, respectively) and weakly with LAA\% $(r=0.32, p=0.010$ and $r=-0.37, p=0.002$, respectively).

\section{Relationships between pulmonary function, IOS, CT and patient-reported outcomes}

Table 2 shows the correlation coefficients for pulmonary function, IOS, CT and patient-reported outcomes. R5R20 and X5 on IOS were weakly to moderately correlated with all three components (symptoms, activity and impacts) and the total of the SGRQ and the MRC scores $(r=0.31-0.51, p<0.01$ and $r=0.27-0.51, p<0.01$, respectively). These relationships were significantly stronger than any other relationships for each component and total of the SGRQ and MRC scores [36].

\section{Results of multiple regression analyses to predict health status and dyspnea}

Table 3 shows the results of stepwise multiple regression analyses to identify variables that could best predict health status and dyspnea. R5-R20 alone accounted for the symptoms, impacts and total of the SGRQ significantly $\left(r^{2}\right.$ (coefficient of determination) $=0.09,0.19$ and 0.24 , respectively). The relationship between R5-R20 and the total SGRQ is shown in Figure 1. The variance of the activity of the SGRQ was most significantly accounted for by X5 $\left(r^{2}=0.26\right)$, and far less so by RV/ TLC $\left(r^{2}=0.02\right)$. For the MRC scores, R5-R20 was the
Table 3 Analysis of the relationships of health status and dyspnea to pulmonary function, IOS and CT by stepwise multiple regression analyses

\begin{tabular}{cccccc}
\hline & \multicolumn{7}{c}{ SGRQ } \\
& symptoms & activity & impacts & total & MRC \\
\hline Independent variables & & & & & \\
FEV 1 & - & - & - & - & 0.03 \\
RV/TLC & - & 0.02 & - & - & 0.02 \\
R5-R20 & 0.09 & - & 0.19 & 0.24 & 0.27 \\
X5 & - & 0.26 & - & - & - \\
LAA\% & - & - & - & - & 0.06 \\
Cumulative ${ }^{2}$ & 0.09 & 0.28 & 0.19 & 0.24 & 0.38 \\
\hline
\end{tabular}

All values represent coefficient of determination $\left(r^{2}\right)$.

Missing data (-) indicate that independent variables were not statistically significant.

$\mathrm{FEV}_{1}$ = forced expiratory volume in one second; RV = residual volume; TLC = total lung capacity; $\mathrm{R}=$ resistance; $\mathrm{X}=$ reactance; $\mathrm{LAA}=$ low attenuation area; $\mathrm{SGRQ}=$ St. George's Respiratory Questionnaire; MRC = Medical Research Council

most significant contributive factor $\left(r^{2}=0.27\right)$, and LAA $\%, \mathrm{FEV}_{1}$, and RV/TLC were found to be only weakly associated $\left(r^{2}=0.06,0.03\right.$ and 0.02 , respectively).

\section{Discussion}

Here, we demonstrated that peripheral airway measurements by IOS (R5-R20 and X5) were significantly correlated with the SGRQ and MRC scores. No measurements of pulmonary function, IOS and CT were significantly correlated with the HADS. Multiple regression analyses revealed that R5-R20 or X5 accounted for the SGRQ and MRC scores more significantly than $\mathrm{FEV}_{1}$ and CT measurements $\left(r^{2}=0.09\right.$ to 0.27$)$. Thus, the novel finding in this study is that peripheral airway measurements by IOS were useful not only for assessing pulmonary impairments but also because they have certain relationships with health status and dyspnea in patients with COPD. IOS is easy to perform, only

Table 2 Analysis of the relationships between pulmonary function, IOS, CT, and patient-reported outcomes

\begin{tabular}{|c|c|c|c|c|c|c|c|}
\hline & \multicolumn{4}{|c|}{ SGRQ } & \multirow[t]{2}{*}{ MRC } & \multicolumn{2}{|c|}{ HADS } \\
\hline & symptom & activity & impacts & total & & anxiety & depression \\
\hline $\mathrm{FEV}_{1}$ & -0.24 & -0.41 & -0.29 & -0.36 & -0.37 & - & - \\
\hline RV/TLC & - & 0.40 & - & 0.29 & 0.46 & - & - \\
\hline$D L_{C O} N_{A}$ & - & - & - & - & - & - & - \\
\hline R20 & - & - & - & - & - & - & - \\
\hline R5-R20 & 0.31 & 0.49 & 0.44 & 0.49 & 0.51 & - & - \\
\hline$\times 5$ & -0.27 & -0.51 & -0.38 & -0.46 & -0.46 & - & - \\
\hline LAA $\%$ & - & 0.27 & - & - & 0.41 & - & - \\
\hline WA\% & - & - & - & - & - & - & - \\
\hline
\end{tabular}

All values represent correlation coefficient $(r)$.

Missing data (-) indicate that there were no statistically significant relationships.

$\mathrm{FEV}_{1}=$ forced expiratory volume in one second; $\mathrm{RV}=$ residual volume; $\mathrm{TLC}=$ total lung capacity; $\mathrm{DL}_{\mathrm{co}}=$ carbon monoxide diffusing capacity; $\mathrm{V}_{\mathrm{A}}=$ alveolar volume $\mathrm{R}=$ resistance; $\mathrm{X}=$ reactance; $\mathrm{LAA}=$ low attenuation area; WA = wall area; SGRQ = St. George's Respiratory Questionnaire; MRC = Medical Research Council; HADS = Hospital Anxiety and Depression Scale 


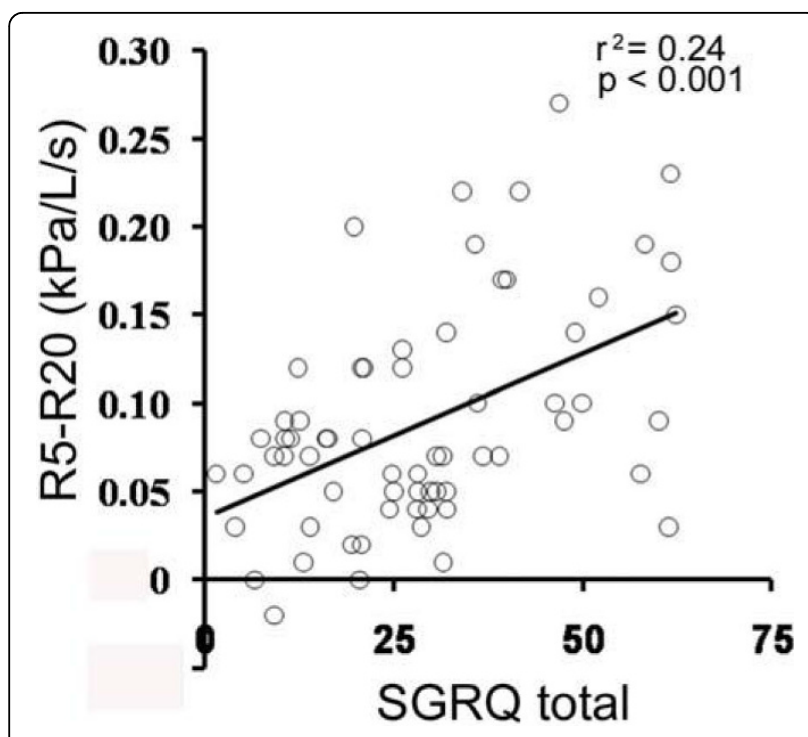

Figure 1 Relationship between R5-R20 and SGRQ total score. R5-R20 showed a significant positive correlation with SGRQ total score $\left(r^{2}=0.24, p<0.001\right)$.

requiring tidal breathing, not forced maneuvers as in conventional pulmonary testing such as spirometry. Therefore, IOS might be considered to be more useful in routine practice for elderly patients with COPD. In fact, IOS was recently used for detecting airway abnormalities and for assessing pharmacological therapeutic efficacy in COPD and other respiratory disorders [11-15,23-27].

Small airway disease (obstructive bronchiolitis) is one of the central pathophysiological features of COPD [1]. Peripheral airway obstruction progressively traps air during expiration, resulting in hyperinflation in COPD [1]. In the present study, peripheral airway measurements (R5-R20 and X5) by IOS consistently correlated with both the degree of airflow limitation $\left(\mathrm{FEV}_{1}\right)$ and the degree of hyperinflation (RV/TLC) due to peripheral airway obstruction. In contrast, large airway function (R20) by IOS was not or only weakly correlated with the degrees of airflow limitation and hyperinflation, and not with health status and dyspnea. In COPD, it is now considered that hyperinflation rather than airflow limitation is the main mechanism for exertional dyspnea [37], and dyspnea is the major determinant of health status $[5,6]$. The significant association between hyperinflation and patient-reported outcomes of dyspnea and poor health status in patients with COPD has recently been reviewed [38]. Thus, the present study indicates that the peripheral airway may be important in determining pulmonary impairment as well as health status and dyspnea to some extent in patients with COPD, which can easily be assessed using IOS.
$\mathrm{CT}$ is also a diagnostic useful method for patients with COPD because it can easily quantitatively assess airway and parenchymal pathology. First, we evaluated WA\%, an index of wall thickening in the large airway, to assess airway function $[20,32,39]$. This parameter can also be used in asthma for correlating airway parameters with disease severity [31]. However, in the present study, WA $\%$ was found not to correlate significantly with the SGRQ and MRC scores, indicating that large airway structural alterations on CT may not accurately reflect patients' perception of functional impairment. Secondly, we used LAA\% on CT as a quantitative index of emphysema, another key feature of COPD. There are some publications [40-42] on the relationship between emphysema and the severity of COPD. However, multiple regression analyses revealed that LAA\% did not or only weakly accounted for the SGRQ and MRC scores, independent of R5-R20 or X5, indicating that emphysema might not be as strong a determinant of health status or dyspnea in COPD as peripheral airway measurements by IOS.

Disturbed psychological status with anxiety and depression is well-known in COPD. Previous studies indicate that it is not significantly correlated with physiological measurements such as $\mathrm{FEV}_{1}$, arterial oxygen pressure, exercise intolerance or daily physical activities $[4,8,43,44]$. Additionally, we show here that, none of the measurements of pulmonary function, IOS or CT was significantly correlated with the HADS. This indicates that psychological status should be evaluated separately from airflow limitation, airway resistance and emphysema.

The values for the coefficient determinations were relatively small in Table 3 (cumulative $r^{2}=0.09$ to 0.38 ), indicating that other factors might be contributing to the outcome. In the present study, we did not assess systemic consequences of COPD, such as exercise capacity and inflammatory biomarkers. These are known to be significantly correlated with health status or dyspnea independently $\mathrm{FEV}_{1}[5-7,45]$. As COPD is regarded as a systemic disease [1], in future, a more comprehensive approach including these parameters might be informative for better understandings the systemic effects of COPD compared to airway diseases.

There are some limitations in this study. First, we used the actual values for IOS for the analysis, as definitive predictive equations have not been established yet [28]. There is a need to perform a large-scale study across a wider age range to validate existing reference values. Second, this study included only male patients, as there are relatively few female patients. This may be due to the gender difference in past smoking trends in Japan, and possibly reflects the present features of Japanese COPD patients. Thus, the generalization of the 
results to females is unwarranted. Third, the number of the patients included in this study was relatively small. However, our results have generated an interesting hypothesis that small airways disease results in certain symptomatology and this must be tested on new cohorts of patients in order to validate the hypothesis.

\section{Conclusions}

In summary, measurements by IOS are significantly correlated with health status and dyspnea in patients with COPD. Therefore, IOS might be useful to manage male COPD patients assessing also their quality of daily life and well-being.

\section{Abbreviations}

COPD: chronic obstructive pulmonary disease; $\mathrm{DL}_{\mathrm{co}}$ : carbon monoxide diffusing capacity; $\mathrm{FEV}_{1}$ : forced expiratory volume in one second; GOLD: Global Initiative for Chronic Obstructive Lung Disease; HADS: Hospital Anxiety and Depression Scale; HRCT: high-resolution computed tomography; IOS: impulse oscillometry; LAA: low attenuation area; MRC: Medical Research Council; R: resistance; RV: residual volume; SGRQ: St. George's Respiratory Questionnaire; TLC: total lung capacity; $V_{\mathrm{A}}$ : alveolar volume; WA: wall area; $\mathrm{X}$ : reactance.

\section{Acknowledgements}

This study was partly supported by the Respiratory Failure Research Group grant from the Ministry of Health, Labor and Welfare, Japan.

\section{Author details}

${ }^{1}$ Department of Respiratory Medicine, Graduate School of Medicine, Kyoto University, Kyoto, Japan. 'Department of Respiratory Care and Sleep Control Medicine, Graduate School of Medicine, Kyoto University, Kyoto, Japan.

\section{Authors' contributions}

$\mathrm{AH}, \mathrm{TO}$ and SM contributed to study design and data acquisition, analysis and interpretation, and prepared the manuscript. TO, SS, SM, DK, KT, MN, EO and YM contributed to data acquisition and critical reviewing of the manuscript. TH, KC and MM supervised the study. All authors read and approved the final manuscript.

\section{Competing interests}

The authors declare that they have no competing interests.

Received: 13 July 2009

Accepted: 7 March 2010 Published: 7 March 2010

\section{References}

1. Rabe KF, Hurd S, Anzueto A, Barnes PJ, Buist SA, Calverley P, Fukuchi Y, Jenkins C, Rodriquez-Roisin R, van Weel C, Zielinski J: Global Initiative for Chronic Obstructive Lung Disease. Global strategy for the diagnosis, management, and prevention of chronic obstructive pulmonary disease: GOLD executive summary. Am J Respir Crit Care Med 2007, 176:532-555.

2. Oga T, Nishimura K, Tsukino M, Saro S, Hajiro T: Analysis of the factors related to mortality in chronic obstructive pulmonary disease: role of exercise capacity and health status. Am J Respir Crit Care Med 2003, 167:544-549.

3. Nishimura K, Izumi T, Tsukino M, Oga T: Dyspnea is a better predictor of 5 -year survival than airway obstruction in patients with COPD. Chest 2002, 121:1434-1440.

4. Ng TP, Niti M, Tan WC, Cao Z, Ong KC, Eng P: Depressive symptoms and chronic obstructive pulmonary disease: effect on mortality, hospital readmission, symptom burden, functional status, and quality of life. Arch Intern Med 2007, 167:60-67.

5. Jones PW: Health status measurement in chronic obstructive pulmonary disease. Thorax 2001, 56:880-887.
6. Hajiro T, Nishimura K, Tsukino M, Ikeda A, Koyama H, Izumi T: Comparison of discriminative properties among disease-specific questionnaire for measuring health-related quality of life in patients with chronic obstructive pulmonary disease. Am J Respir Crit Care Med 1998, 157:785-790.

7. Hajiro T, Nishimura K, Tsukino M, Ikeda A, Koyama H, Izumi T: Analysis of clinical methods used to evaluate dyspnea in patients with chronic obstructive pulmonary disease. Am J Respir Crit Care Med 1998, 158:1185-1189.

8. Light RW, Merrill EJ, Despars JA, Gordon GH, Mutalipassi LR: Prevalence of depression and anxiety in patients with COPD. Relationship to functional capacity. Chest 1985, 87:35-38.

9. Borrill ZL, Houghton CM, Woodcock AA, Vestbo J, Singh D: Measuring bronchodilation in COPD clinical trials. Br J Clin Pharmacol 2005 59:379-384.

10. Borrill ZL, Houghton CM, Tal-Singer R, Vessey SR, Faiferman I, Langley SJ, Singh $D$ : The use of plethysmography and oscillometry to compare long-acting bronchodilators in patients with COPD. Br J Clin Pharmacol 2007, 65:244-252.

11. Park JW, Lee YW, Jung YH, Park SE, Hong CS: Impulse oscillometry for estimation of airway obstruction and bronchodilation in adults with mild obstructive asthma. Ann Allergy Asthma Immunol 2007, 98:546-552.

12. Houghton CM, Lawson N, Borrill ZL, Wixon CL, Yoxall S, Langley SJ, Woodcock A, Sigh D: Comparison of the effects of salmeterol/fulticasone propionate with fluticasone propionate on airway physiology in adults with mild persistent asthma. Respir Res 2007, 8:52

13. Mansur AH, Manney S, Ayres JG: Methacholine-induced asthma symptoms correlate with impulse oscillometry but not spirometry. Respir Med 2008, 102:42-49.

14. Oppenheimer BW, Goldring RM, Herberg ME, Hofer IS, Reyfman PA, Liautaud S, Rom WN, Reibman J, Berger Kl: Distal airway function in symptomatic subjects with normal spirometry following World Trade Center dust exposure. Chest 2007, 132:1275-1282.

15. Skloot G, Goldman M, Fischler D, Goldman C, Schechter C, Levin S, Teirstein A: Respiratory symptoms and physiologic assessment of ironworkers at the World Trade Center Disaster Site. Chest 2004 125:1248-1255

16. King GG, Salome CM: Multimodality measurements of small airways disease. Eur Respir J 2006, 27:250-252.

17. Hellinckx J, Cauberghs M, De Boeck K, Demedts M: Evaluation of impulse oscillation system: Comparison with forced oscillation technique and body plethysmography. Eur Respir J 2001, 18:564-570.

18. Sherter CB, Connolly JJ, Schilder DP: The significance of volume-adjusting the maximal midexpiratory flow in assessing the response to a bronchodilator drug. Chest 1978, 73:568-571.

19. Hogg JC, Chu F, Utokaparch S, Woods R, Elliott WM, Buzatu L, Cherniack RM, Rogers RM, Sciurba FC, Coxson HO, Pare PD: The nature of small-airway obstruction in chronic obstructive pulmonary disease. $\mathrm{N}$ Engl J Med 2004, 350:2645-2653.

20. Hasegawa M, Nasuhara $Y$, Onodera $Y$, Makita H, Nagai $K$, Fuke S, Ito $Y$, Betsuyaku T, Nishimura M: Airflow limitation and airway dimensions in chronic obstructive pulmonary disease. Am J Respir Crit Care Med 2006, 173:1309-1315

21. Hogg JC, Chu FS, Tan WC, Sin DD, Patel SA, Pare PD, Martinez FJ, Rogers RM, Make BJ, Criner GJ, Cherniack RM, Sharafkhaneh A, Luketich JD, Coxson $\mathrm{HO}$, Elliott WM, Sciurba FC: Survival after lung volume reduction in chronic obstructive pulmonary disease: insights from small airway pathology. Am J Respir Crit Care Med 2007, 176:454-459.

22. Nakano Y, Muro S, Sakai H, Hirai T, Tsukino M, Tsukino M, Nishimura K, Ito H, Pare PD, Hogg JC, Mishima M: Computed tomographic measurements of airway dimensions and emphysema in smokers. Correlation with lung function. Am J Respir Crit Care Med 2000, 162:1102-1108.

23. Nieto A, Pamies R, Oliver F, Medina A, Caballero, Mazon A: Montelukast improves pulmonary function measured by impulse oscillometry in children with asthma (Mio study). Respir Med 2006, 100:1180-1185.

24. Goldman MD, Saadeh C, Ross D: Clinical applications of forced oscillation to assess peripheral airway function. Respir Physiol Neurobiol 2005, 148:179-194.

25. Smith HJ, Reinhold P, Goldman MD: Forced oscillation technique and impulse oscillometry. Eur Respir Mon 2005, 31:72-105. 
26. Yamaguchi $M$, Niimi $A$, Ueda $T$, Takemura $M$, Matsuoka $H$, Jinnai $M$, Otsuka K, Oguma T, Takeda T, Ito I, Matsumoto H, Hirai T, Chin K, Mishima M: Effect of inhaled corticosteroids on small airways in asthma: Investigation using impulse oscillometry. Pulm Pharmacol Ther 2009, 22:326-332.

27. Cao J, Que C, Wang G, He B: Effect of posture on airway resistance in obstructive sleep apnea-hypopnea syndrome by means of impulse oscillation. Respiration 2009, 77:38-43.

28. Kolsum U, Borill Z, Roy K, Starkey C, Vestbo J, Houghton C, Singh D: Impulse oscillometry in COPD: identification of measurements related to airway obstruction, airway conductance and lung volumes. Respir Med 2009, 103:136-143

29. Sakai N, Mishima M, Nishimura K, Ito H, Kuno A: An automated method to assess the distribution of low attenuation areas on chest CT scans in chronic pulmonary emphysema patients. Chest 1994, 106:1319-1325.

30. Ohara T, Hirai T, Sato S, Sato A, Nishioka M, Muro S, Mishima M: Comparison of airway dimensions in different anatomic locations on chest CT in patients with COPD. Respirology 2006, 11:579-585.

31. Niimi A, Matsumoto $H$, Amitani R, Nakano Y, Nishimura M, Minakuchi M, Nishimura K, Itoh H, Izumi T: Airway wall thickness in asthma assessed by computed tomography. Relation to clinical indices. Am J Respir Crit Care Med 2000, 162:1518-1523.

32. Jones PW, Quirk FH, Baveystock CM, Littlejohns P: A self-complete measure of health status for chronic airflow limitation: the St. George's Respiratory Questionnaire. Am Rev Respir Dis 1992, 145:1321-1327.

33. Brooks SM: Surveillance for respiratory hazards. ATS News 1982, 8:12-16.

34. Zigmond AS, Snaith RP: The hospital anxiety and depression scale. Acta Psychiatr Scand 1983, 67:361-370.

35. Mahler DA, Wells CK: Evaluation of clinical methods for rating dyspnea. Chest 1988, 93:580-586

36. Cohen J, Cohen P: Applied multiple regression/correlation analysis for the behavioral sciences. Lawrence Erlbaum Assoc Inc, Hillsdale, N.J, 2 1983, 56-57.

37. O'Donnell DE, Revill SM, Webb KA: Dynamic hyperinflation and exercise intolerance in chronic obstructive pulmonary disease. Am J Respir Crit Care Med 2001, 164:770-777.

38. Cooper CB: The connection between chronic obstructive pulmonary disease symptoms and hyperinflation and its impact on exercise and function. Am J Med 2006, 119:21-31.

39. Orlandi I, Moroni C, Camiciottoli G, Bartolucci M, Pistolesi M, Villari N, Mascalchi M: Chronic obstructive pulmonary disease: Thin-section CT measurement of airway wall thickness and lung attenuation. Radiology 2005, 234:604-610.

40. Boschetto P, Miniati M, Miotto D, Braccioni F, De Rasa E, Bononi J, Papi A, Saetta M, Fabbri LM, Mapp CE: Predominant emphysema phenotype in chronic obstructive pulmonary. Eur Respir J 2003, 21:450-454.

41. Boschetto P, Quintavalle S, Zeni E, Leprotti S, Potena A, Ballerin L, Papi A, Palladini G, Luisetti M, Annovazzi L, ladarola P, De Rosa E, Fabbri LM, Mapp CE: Association between markers of emphysema and more severe chronic obstructive pulmonary disease. Thorax 2006, 61:1037-1042.

42. Makita H, Nasuhara $Y$, Nagai $K$, Ito $Y$, Hasegawa M, Betsuyaku T, Onodera $Y$, Hizawa N, Nishimura M: Characterisation of phenotypes based on severity of emphysema in chronic obstructive pulmonary disease. Thorax 2007, 62:932-937.

43. Janssens JP, Rochat T, Frey JG, Dousse N, Pichard C, Tschopp JM: Healthrelated quality of life in patients under long-term oxygen therapy: A home-based descriptive study. Respir Med 1997, 91:592-602.

44. Borak J, Sliwinski P, Piasecki Z, Zielinski J: Psychological status of COPD patients on long term oxygen therapy. Eur Respir J 1991, 4:59-62.

45. Garrod R, Marshall J, Barley E, Frederick S, Hagan G: The relationship between inflammatory markers and disability in chronic obstructive pulmonary disease. Prim Care Respir J 2007, 16:236-240.

\section{Pre-publication history}

The pre-publication history for this paper can be accessed here:http://www biomedcentral.com/1471-2466/10/10/prepub

doi:10.1186/1471-2466-10-10

Cite this article as: Haruna et al:: Relationship between peripheral airway function and patient-reported outcomes in COPD:

a cross-sectional study. BMC Pulmonary Medicine 2010 10:10

\section{Submit your next manuscript to BioMed Central and take full advantage of:}

- Convenient online submission

- Thorough peer review

- No space constraints or color figure charges

- Immediate publication on acceptance

- Inclusion in PubMed, CAS, Scopus and Google Scholar

- Research which is freely available for redistribution 